\section{Mathematica \\ Mathematica}

A System for Doing Mathematics by Computer

A Wolfram Research Inc. product

$\square$ Numerics - Works with numbers of arbitrary magnitude and precision.

$\square$ Symbolics - Encyclopaedia of mathematical functions and operations used in arithmetic, algebra and analysis.

Procedural, functional and mathematical programming.

$\square$ Graphics - 2D, 3D and animated PostScript graphics.

$\square$ Text processing - Fully interactive reports and textbooks.

$\square$ Runs on - MS-DOS based computers; Macintosh, Apollo, Hewlett Packard, IBM AIX/RT, MIPS, Silicon Graphics, Sony, Sun, VAX.

Now available in Europe from:

MathSoft Overseas, Inc.

POB 641, 1211 Geneva 3, Switzerland Tel. ++41 (22) 465260

Fax $++41(22) 465939$

\section{International School \\ for Quantum Electronics \\ 15th Course (sponsored by NATO) \\ "Laser Systems for Photobiology and Photomedicine" \\ 11-20 May 1990 \\ Erice, Italy \\ Contact: \\ A.-M. Scheggi, IROE-C.N.R., \\ Via Panciatichi 64, 1-50127 Firenze \\ Applications by 2.4 .90 / \$US 500.- all inclusive.}

The time has also come to consider a second modernisation programme for the 1990's. The first, launched twelve years ago, has now been completed. Dr. Peter Day, professor of solid state chemistry at Oxford University who succeeded the German alternate, Professor Wolfgang Glässer, as Director on 1 October 1989 will submit a proposal for modernisation to the ILL's steering committee in a few weeks.

\section{Heraeus-Stiftung Grant}

Following an initiative by Prof. W. Buckel and the generosity of the Dr. Wilhelm Heinrich Heraeus und Else Heraeus-Stiftung, a one-time amount of DM 50000. - has been granted by the German Physical Society to the EPS to improve the role of Europhysics News in providing scientific communication among Europe's physicists.

\title{
Full professor in Rheology
}

The department of Applied Physics has an opening for a full professor in Rheology.

The teaching and research are focussed on the rheological constitutive equations of liquid-like materials and the relationship between these equations and the microscopic and/or the molecular structure of materials with emphasis on the physical mechanical aspects. The nature of the research is both theoretical and experimental. The applications are in the field of characterisation and development of materials. Experimental techniques necessary for the research. applications and the development of advanced instruments are involved.

The appointee is expected to show an active interest in the current projects and will be expected to give guidance to staff and research students; to participate in the teaching curriculum: to take part in the university administration and management: and to seek financial support from public funds. We would expect fluency in the Dutch language in a period of two years.

The salary will be in the range of Dfl. 8.957,-to Dfl. 9.957,--per month (scale A).

Letters of application including a full curriculum vitae and a list of publications should be sent within four weeks of the publication of this advertisement to the chairman of the nominating committee prof.dr. A. van Silfhout, Department of Applied Physics. Twente University of Technology. P.O. Box 217. $7500 \mathrm{AE}$ Enschede. the Netherlands.

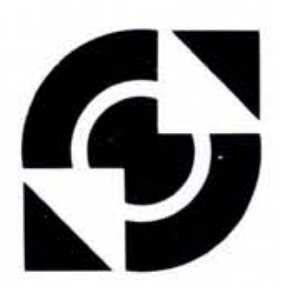

\section{Twente University}

\section{Telex Discontinued}

The very reduced number of telexes received and sent by the EPS Secretariat in Geneva no longer justifies the expense of maintaining a telex link. Adequate telefax facilities are available in all but one or two European countries and the situation is improving daily.

So... the telefax number remains the same $(++41-22-7931317)$ and the telex link will not be available after 31 March 1990.

\section{Gentner-Kastler Prize}

The winner of the Gentner-Kastler Prize for 1990, awarded jointly by the German and French Physical Societies, last month. He is Pierre Bergé of the Centre d'Etudes Nucléaires, Saclay for his successful investigations of critical phenomena dynamics in binary mixtures and for outstanding research in the field of chaos in nonlinear systems. 